\title{
Spectral Analysis of the Svalbard Temperature Record 1912-2010
}

\author{
Ole Humlum, ${ }^{1,2}$ Jan-Erik Solheim, ${ }^{3}$ and Kjell Stordahl ${ }^{4}$ \\ ${ }^{1}$ Department of Geosciences, University of Oslo, P.O. Box 1047 Blindern, N-0316 Oslo, Norway \\ ${ }^{2}$ Department of Geology, University Centre in Svalbard (UNIS), P.O. Box 156, N-9171 Longyearbyen, Svalbard, Norway \\ ${ }^{3}$ Department of Physics and Technology, University of Tromsø, N-9037 Tromsø, Norway \\ ${ }^{4}$ Telenor Norway, Finance, N-1331 Fornebu, Norway
}

Correspondence should be addressed to Ole Humlum, ole.humlum@geo.uio.no

Received 14 September 2011; Revised 14 December 2011; Accepted 20 December 2011

Academic Editor: Igor N. Esau

Copyright ( $) 2011$ Ole Humlum et al. This is an open access article distributed under the Creative Commons Attribution License, which permits unrestricted use, distribution, and reproduction in any medium, provided the original work is properly cited.

\begin{abstract}
Climate development with possible anthropogenic effects occurs on a background of natural climatic variations, which may be considerable, and especially in the Arctic. Natural climate variations however remain poorly understood, although they remain important for discriminating between natural and anthropogenic influences on current climate change. Using the Svalbard $\left(78^{\circ} \mathrm{N}\right)$ surface air temperature record 1912-2010 as an example, we here suggest a road ahead to identify and describe such natural climate variations. By means of Fourier and wavelet analysis the record is decomposed into time-frequency space, to extract information on periodic signals and their amplitude and variation over time. By this we identify several cyclic variations on the time scale investigated. These oscillations are present in the annual record, as well as in seasonal subsets of the record. Using only three oscillations it is possible to hindcast the Svalbard temperature record well. We suggest that such persistent oscillations may be used for forecasting the overall features of future temperature changes for a limited period, about $10-25 \%$ of the record length. Our main focus is on identifying the character of recurrent natural temperature variations, but we also comment briefly on possible physical explanations for some of the identified cyclic variations.
\end{abstract}

\section{Introduction}

Climate science is a composite science that draws on theory and method from an astonishingly wide range of related disciplines. It, however, shares with other sciences a clearly definable general objective, succinctly defined by Braithwaite [1] as "To establish general laws covering the behaviour of empirical events or objects ... and thereby to enable us to connect together our knowledge of separately known events, to make reliable predictions of events as yet unknown."

In accordance with Faegri's [2] empirical law-the longer the period of climatic change, the wider the area similarly affected - we can expect that for a long period, say an Ice Age, the temperature change would encompass the entire globe, while for shorter periods of change, the change would only include correspondingly smaller areas. Over short periods of time, of the order of decades only, the climatic change over one region could differ even more from that of another nearby. The climatic record must consequently be studied region by region to establish the different characteristics of change in each individual region, both for ensuring correct input in climate models and for establishing an orderly sequence of past climatic changes as a basis for their possible prediction [3].

Here, we will concern ourselves with the climatic changes during the last 98 years in the Svalbard region of the Arctic, by attempting to identify recurrent, natural temperature variations documented by the Svalbard 1912-2010 meteorological record. Our main focus is the mean annual surface air temperature (MAAT), although we will also consider the two seasonal subsets (DJF; winter) and (JJA; summer) of this record.

Most meteorological series display significant decadal or multiyear periodic behaviour, which so far have not been fully included in analytic climate models (see, e.g., Solomon et al. [5]), mainly because of still incomplete knowledge on the detailed character of such variations. For example, the Pacific Oscillation that gives rise to El Niño and La Ninã has been known for over a century, and in the North Atlantic a similar oscillation, the North Atlantic Oscillation (NAO), is known to influence weather in this region. In addition, from several different environmental records an 


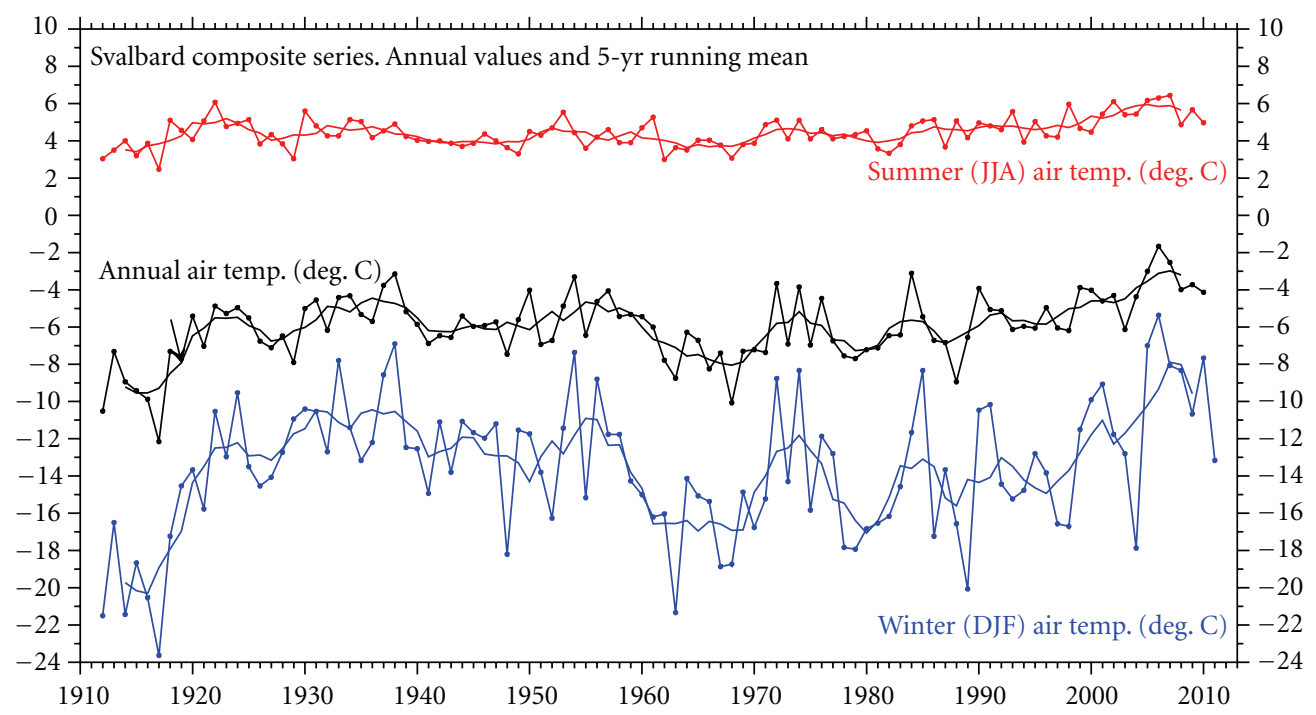

FIGURE 1: The Svalbard temperature record 1912-2010 [4], showing the mean annual air temperature (MAAT), the average summer temperature (JJA), and the average winter temperature (DJF). Thin lines show annual values, and thick lines show the simple $5 \mathrm{yr}$ average. The linear MAAT increase $1912-2010$ is $0.23^{\circ} \mathrm{C}$ per decade.

about 60 yr climate cycle is known (see, e.g., Klyashtorin and Lyubushin [6]). Thus, during the last few years there has been an increasing realisation of important oscillatory phenomena in the earth's global weather system, not the least as knowledge on such cyclic variations is important to discriminate between natural and anthropogenic influences on current climate change. This suggests that an attempt of identifying cyclic variations is timely for improving understanding of past, present, and future climate variations.

To exemplify how natural, cyclic temperature variations might be identified and analysed, we here first present the Svalbard meteorological record 1912-2010, followed by a brief introduction to the wavelet and Fourier analysis techniques, before proceeding to a spectral analysis of the Svalbard record. We chose to focus on one temperature series instead of using averaged series covering larger regions, such as, for example, global or hemispheric series. We do this because the common procedure of averaging individual data series with different levels of autocorrelation may change the statistical structure of the resulting averaged time series notably, compared to the original series, an issue previously pointed out by Polyak [7]. The present analysis is building on an initial and broader analysis [4], but here we take a more detailed view on the Svalbard record, including issues relating to statistical significance and seasonal subsets of the record.

\section{The Svalbard Temperature Record}

Special climatic interest has often been attached to the Svalbard region because of the high latitude and the fact that this part of the Arctic apparently displays an extraordinary high climatic variability, partly reflecting global temperature trends. This was recognized early by both Ahlmann [8] and Lamb [9], and later by Rogers et al. [10], but also in the third IPCC report [11] attention was again drawn to the high climatic sensitivity of the Svalbard region.

Climatic variations in Svalbard during the 20th century are documented by monthly meteorological data since November 1911 by Førland et al. [12], and the Svalbard record (Figure 1) is the longest meteorological record from the High Arctic. The modern official Svalbard meteorological station is located near the main settlement in Svalbard, Longyearbyen $\left(78^{\circ} 13^{\prime} \mathrm{N}, 15^{\circ} 33^{\prime} \mathrm{E}\right.$, about 2000 inhabitants), in central Spitsbergen. The station is located at the Svalbard Airport ( $24 \mathrm{~m}$ asl.), about $3 \mathrm{~km} \mathrm{NW}$ of Longyearbyen, near the shore of the large fjord Isfjorden. Monthly temperature data were obtained from the eKlima portal run by the Norwegian Meteorological Institute, and MAAT, DJF, and JJA values of 1912-2010 calculated from this.

The Svalbard record is a homogenized composite record, established from observations made at different stations in central Spitsbergen, mainly around the large fjord Isfjorden, extending from the west coast to interior Spitsbergen. The individual meteorological stations have been described by Hanssen-Bauer et al. [13], and a survey of meteorological statistics for the Norwegian Arctic presented by Førland et al. [12]. It is generally difficult to establish reliable long-term meteorological series from Arctic areas, as weather observations here primarily are aimed for forecasting purposes, and usually little care is taken to prevent inhomogeneities caused by relocations, change in local environment (buildings), and instrumental changes (Nordli et al. [14]). In addition, the station network in the Arctic is sparse, so it is often difficult to find good reference series for use in homogeneity studies.

To overcome these difficulties and to homogenise meteorological time series from Svalbard, Nordli et al. [14] used data from several North Atlantic regions in the homogeneity testing of the Svalbard series. The following stations were used as reference: Tromsø (Norway), Vardø (Norway), Makkaur Lighthouse (Norway), Ekkerøy (Norway), 
Longyearbyen (Svalbard), Stykkisholmur (Iceland), Teigarhorn (Iceland), Scoresbysund (Greenland), and Ammassalik (Greenland). In addition, data from parallel Svalbard measurements and metadata archives was used as supplementary information. The Standard Normal Homogenity Test (Alexandersson [15], Hanssen-Bauer and Førland [16]) was applied on the series, and the results were validated by a study of the individual stations history. By this homogenity monthly series for air temperature and precipitation were established for Svalbard Airport back to late 1911 [14]. The absence of visible irregularities in the Svalbard temperature record itself (Figure 1) as well as in the wavelet diagrams (Figures 3 and 5), corresponding to the timing of known station changes, testifies to the quality of the homogenisation carried out.

A prominent feature of the homogenised Svalbard temperature record is a marked warming 1917-1922, which changed MAAT at sea level from about $-12.2^{\circ} \mathrm{C}$ to $-4.9^{\circ} \mathrm{C}$. However, it is not known if the low starting temperature in the record (Figure 1) is typical for Little Ice Age conditions in Svalbard, or if it only represents the culmination of a decalscale cold period in the transition to warmer conditions following the Little Ice Age. Comparisons with early records from northern Norway (e.g., Alta Airport, $70.0^{\circ} \mathrm{N} 23.4^{\circ} \mathrm{E}$, 1880-1939; Vard $\varnothing, 70.37^{\circ} \mathrm{N} 31.10^{\circ} \mathrm{E}, 1840-2010$; MehavenSletnes, $\left.71.9^{\circ} \mathrm{N} 27.8^{\circ} \mathrm{E}, 1899-1940\right)$ suggest that this might well be the case. Judging from these stations, Svalbard MAAT in the decade leading up to 1912 presumably was 1 to $3^{\circ} \mathrm{C}$ above what was recorded between 1912 and 1917. If so, the linear trend of $0.23^{\circ} \mathrm{C}$ per decade calculated for the 1912 2010 Svalbard MAAT record indicates an unrealistic high overall temperature increase rate for the past century. If one instead calculates the trend between the two temperature peaks in 1938 and 2006, the linear decadal trend is $0.14^{\circ} \mathrm{C}$ only. Clearly it is precarious to calculate an overall trend from a low to a peak value. We will briefly return to this issue later.

Following the 1917-1922 temperature rise, the Svalbard record is characterised by a warm period lasting until around 1955 , a relatively cold period lasting to about 1990, and a renewed warming lasting until at least 2006. A number of decadal-scale variations are apparently superimposed on this overall pattern of change. From Figure 1, it is seen that MAAT variations mainly are derived from variations in winter temperature, and that the summer temperature shows small variations only. Since about 1990 the Svalbard MAAT has increased about $3-4^{\circ} \mathrm{C}$, but it is not possible to determine if this temperature increase is the leading edge of a more permanent increase as suggested by climate models, or merely represents a typical decadal-scale oscillation. Indeed, decreasing MAAT since 2006 suggests an oscillation.

\section{Fourier and Wavelet Analyses}

Visual inspection of climate data series often suggests the existence of recurrent variations, and Fourier analysis represents a valuable tool for the identification of such natural variations. However, describing the character (persistence, period and amplitude) of cyclic patterns might be difficult as they often come and go, lasting only for a limited period at each appearance. Especially the dynamics over time of the individual cycles can be complicated to analyse. For this reason, oscillations may prove difficult to characterise fully from a normal Fourier power spectrum. To overcome the problem encountered when cyclic variations change their period and amplitude, we therefore employed wavelet analysis [17] to identify and describe oscillating variations in the Svalbard temperature record as a supplement to the Fourier analysis. A more thorough description of the wavelet analysis is given by Torrence and Compo [18] and by Humlum et al. [4]. Wavelet analysis has previously been brought into use in climate studies (e.g., Lau and Weng [19], Torrence and Compo [18], Baliunas et al. [20], Isaksson et al. [21], Butler et al. [22], Chylek et al. [23], and Humlum et al. [4]), but until now the technique only has received modest interest from the climate community in general.

In general, according to the Nyquist-Shannon sampling theorem [24], only frequencies lower than $f_{s} / 2$ should be considered in the analysis, where $f_{s}$ is representing the sampling frequency. As an example, for a data series representing annual values only frequencies lower than $0.5 \mathrm{yr}^{-1}$ should be considered, corresponding to periods longer than $2 \mathrm{yr}$.

\section{Fourier Analysis of the Svalbard MAAT Record}

Before carrying out a Fourier analysis on the Svalbard MAAT series, the data series was taken at face value and the 19122010 linear trend of $0.23^{\circ} \mathrm{C}$ was removed. The result of the Fourier analysis is shown in Figure 2. The Svalbard MAAT record is seen to be dominated by three periods of about 68.4, 25.7, and $16.8 \mathrm{yr}$ length, all with amplitude greater than $0.8^{\circ} \mathrm{C}$. In addition to these three dominant periods, five periods with amplitude about $0.5^{\circ} \mathrm{C}$ are also present in the spectra. These periods have lengths of about 36.7, 12.3, 8.7, 5.1 , and $2.5 \mathrm{yr}$, respectively.

The significance levels shown in Figure 2 are peak-based critical limit significance levels, which are of particular merit in ascertaining the significance of the largest spectral component [25]. In this type of test, one seeks to disprove the null hypothesis postulating either a white noise signal with no autocorrelation $(\operatorname{AR}(1)=0.0)$, or a red noise signal with autocorrelation $(\operatorname{AR}(1)>0.0)$. Red noise is present when the background power decreases with increasing frequency, and the autoregressive value is a measure of the similarity between observations in a time series as a function of the time separation between them. For the Svalbard 1912-2010 MAAT series the AR coefficient was determined to 0.48.

With the background set, the peak spectral power was then compared against the various critical limits (Figure 2). A $90 \%$ critical limit is that level where in only 1 of 10 separate random noise signals the highest peak would achieve this height strictly due to random chance. Likewise, for a peak reaching the $50 \%$ critical limit there is a $50-50$ probability that this could have arisen strictly from chance. The critical limit test used here is different from traditional confidence or significance levels that apply to a single data set only. For example, a standard $90 \%$ confidence limit would specify a level where $10 \%$ of the points in a single spectrum would 


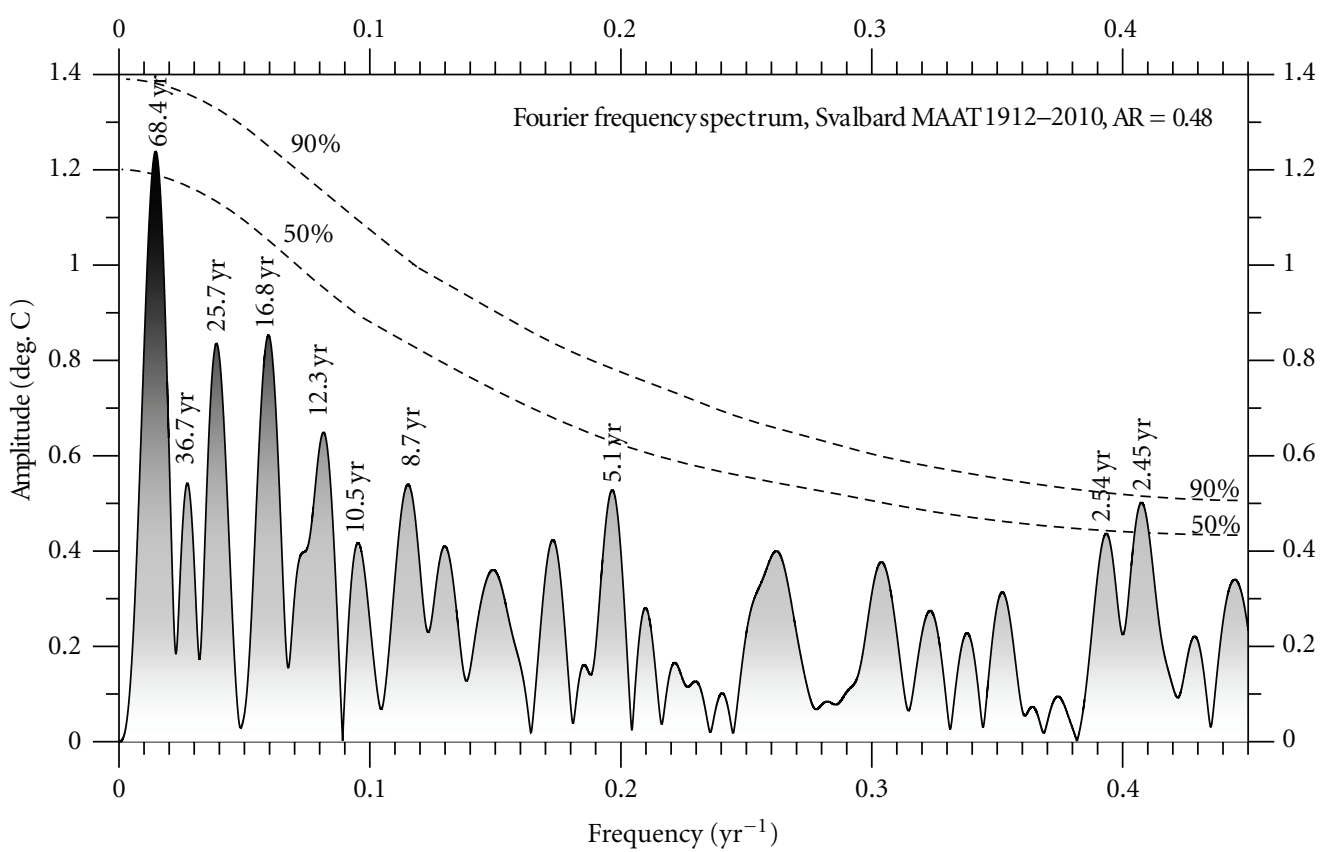

FIgURE 2: Fourier analysis (using Best Exact N composite algorithm) of the detrended Svalbard 1912-2010 MAAT series. The record is dominated by three periods of about $68.4,25.7$, and $16.8 \mathrm{yr}$ length, all with amplitude greater than $0.8^{\circ} \mathrm{C}$. In a statistical sense; however, the $2.45 \mathrm{yr}$ peak is most important. The stippled lines indicate peak-based critical limit significance levels, while the grey tone indicates increasing amplitude. Only frequencies lower than $0.45 \mathrm{yr}^{-1}$ are shown.

be expected to lie above this height strictly due to random chance.

Exposed to the critical limit test none of the frequency peaks shown in Figure 2 are statistically very strong. Only the $2.45 \mathrm{yr}$ peak approaches the $90 \%$ critical limit, and for that reason the alternative null hypothesis, that the observed oscillations represent noise, cannot be rejected using the peak-based critical limit test. However, this does not imply that the oscillations observed are red noise, but merely that the evidence is too weak to demonstrate their statistical significance. Further, as we later will demonstrate by wavelet analysis, the reason for the weak Fourier peak strength is partly that few of the oscillations are entirely stable over time, but instead vary somewhat in strength and frequency. By this their Fourier peak strength is reduced. A similar observation lead Polyak [7] to suggest that such periods might represent random phenomena only. However, as several of the strongest oscillations seen in Figure 2 recur in data from other stations within the North Atlantic region (Humlum et al. [26]), we imply that the Svalbard temperature signal is not entirely random. In addition, the effect (the amplitude) of at least three of the identified oscillations is large $\left(>0.8^{\circ} \mathrm{C}\right)$, and these oscillations are therefore not unimportant. Even though their significance only is close to the $50 \%$ critical limit, they remain important to understand the Svalbard MAAT series. Likewise, it is possible for a statistical significant factor to be of little practical importance if the effect of the factor is small.

Strong periods like the 68.4, 25.7, and $16.8 \mathrm{yr}$ periods may have weaker harmonics if they are not perfect sine variations, which might explain some of the shorter periods found by the Fourier analysis, for example, 36.7, 12.3, and
$8.7 \mathrm{yr}$, respectively. Such shorter periods may therefore not be providing new information as to their origin, except that the fundamental variation deviates from being a perfect sine variation. On the other hand, an observed potential harmonic variation needs not to be derived from a longer oscillation, but may represent an independent oscillation. Great care should therefore be exercised when interpreting spectral information like shown in Figure 2.

As to the possible origin of some of these periods, the $10.5 \mathrm{yr}$ period with about $0.4^{\circ} \mathrm{C}$ amplitude may possibly represent a solar signal in the record, while the stronger $8.7 \mathrm{yr}$ period is nearly identical to a well-known lunar orbital period $(8.85 \mathrm{yr})$ and may therefore not be a harmonic of the longer $16.8 \mathrm{yr}$ period, but a real oscillation in its own rights. The possible origin of some of the other identified periods will be discussed further below. The $2.45 \mathrm{yr}$ oscillation is strong both in a statistical sense and with regard to amplitude. This explains why seldom more than two very cold or warm years in a row are recorded in Svalbard.

\section{Wavelet Analysis of the Svalbard MAAT Record}

Before analysing the Svalbard temperature record it was detrended by fitting a linear trend 1912-2010 to the data and then subtracting this from the data. The detrended data set was then decomposed by a continuous wavelet transform, whereby a time-frequency representation of the embedded signals was constructed with good time and frequency resolution. As the Fourier analysis (Figure 2) suggested the existence of more than 10 oscillations with amplitude of at least $0.4^{\circ} \mathrm{C}$ in the data set, we specified a wave number of 10 . 


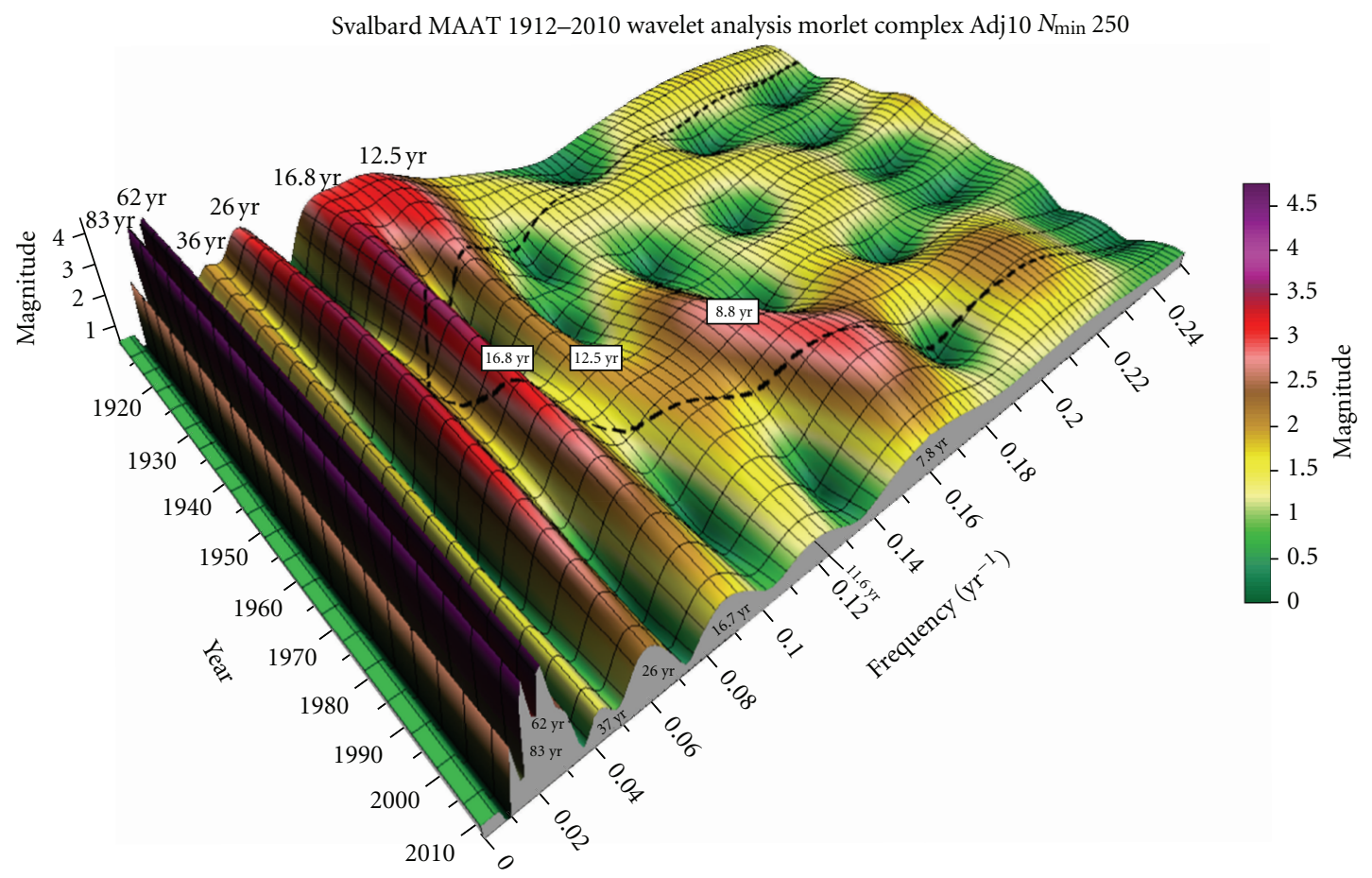

Figure 3: Diagram showing the continuous wavelet time-frequency spectrum for the Svalbard MAAT series 1912-2010 [4]. Time (AD) and frequency $\left(\mathrm{yr}^{-1}\right)$ of cyclic variations embedded in the temperature data are shown along the horizontal axes. Frequencies higher than $0.25 \mathrm{yr}^{-1}$ are not shown, corresponding to showing only periods longer than $4 \mathrm{yr}$. The vertical axis (and colour scale) shows the magnitude of the Continuous Wavelet Spectrum at a given time and frequency. The magnitude is calculated as sqrt $(\operatorname{Re} * \operatorname{Re}+\operatorname{Im} * \operatorname{Im})$, where $\operatorname{Re}$ is the real component of a given segment's FFT at a given frequency and Im is the imaginary component. Usually the magnitude is 3-4 times the corresponding amplitude. The dotted line indicates the extent of the cone of influence, where the magnitude of oscillations may be diminished artificially due to zero padding, especially towards the ends of the time scale, see, for example, the 26 and 7.8 yr period.

Figure 3 shows the complex component of the wavelet in the time and frequency domain for the Svalbard MAAT record. This type of wavelet diagram has constant power across the time duration of the individual oscillations, achieved by combining both positive and negative peaks (the real component) into a single peak, and thereby more clearly than the real component showing the extent of the identified oscillations in both the time and frequency domain. As we used zero padding (extending the data series with zeros at the end) to eliminate wraparound artefacts for especially low frequencies, spectral powers may be diminished somewhat within the cone of influence compared to their real values.

The wavelet analysis revealed several cyclic variations in the Svalbard MAAT record. Since 1912 four dominant periods of about $83,62,26$, and $16.8-16.7 \mathrm{yr}$ characterise the entire record. Both the about 83 and 62 yr oscillations are strong and persistent, but they are entirely located within the cone of influence. The about 26 and $16.8-16.7 \mathrm{yr}$ oscillations are strong, but are moving towards somewhat less influence in recent years. A weaker oscillation of about $36-37 \mathrm{yr}$ is also visible in the record, but with decreasing influence in recent years. However, the recent apparent decrease in spectral powers for these periods may be an artefact derived from zero padding.

A couple of shorter oscillations were also identified in the Svalbard MAAT record: about 12.5-11.6 and 8.8-7.8 yr. However, in contrast to the above oscillations periods, these shorter oscillations do not represent stable phenomena, which is why they do not show up with similar strength in the Fourier analysis (Figure 2). The $12.5 \mathrm{yr}$ period was initially strong, but the signal declined somewhat in magnitude and period (now 11.6 yr) over the observational period. However, the decline of magnitude may partly be an artefact of zero padding, but not the gradual change of frequency. Concurrent with this development, the about $8.8 \mathrm{yr}$ period increased in importance until around 1985, after which a weakening apparently has begun, although perhaps also a zero padding effect. At the same time a slight frequency increase has taken place, so the modern period length is somewhat shorter, about $7.8 \mathrm{yr}$. Analyses of the real component (not shown here) demonstrate that both oscillations presently are near their minimum power, and they are presumably going to gain importance in the coming years. The shorter periods all are relatively weak, and the main control on the Svalbard MAAT record has always been the longer periodic variations; especially the 83, 62, 26, and 16.8-16.7 yr cycles (Figure 3). In addition to the periods shown in Figure 3 (truncated at $4 \mathrm{yr}$ ), the about $2.5 \mathrm{yr}$ period found by the Fourier analysis (Figure 2) was also identified by the wavelet analysis. This period was strong mainly between 1965 and 1980, and less so since then.

Most of the periods identified by the wavelet analysis are also recognised by the Fourier analysis (Figure 2). However, some of the periods may be interrelated: the $62,37-36,26$, 


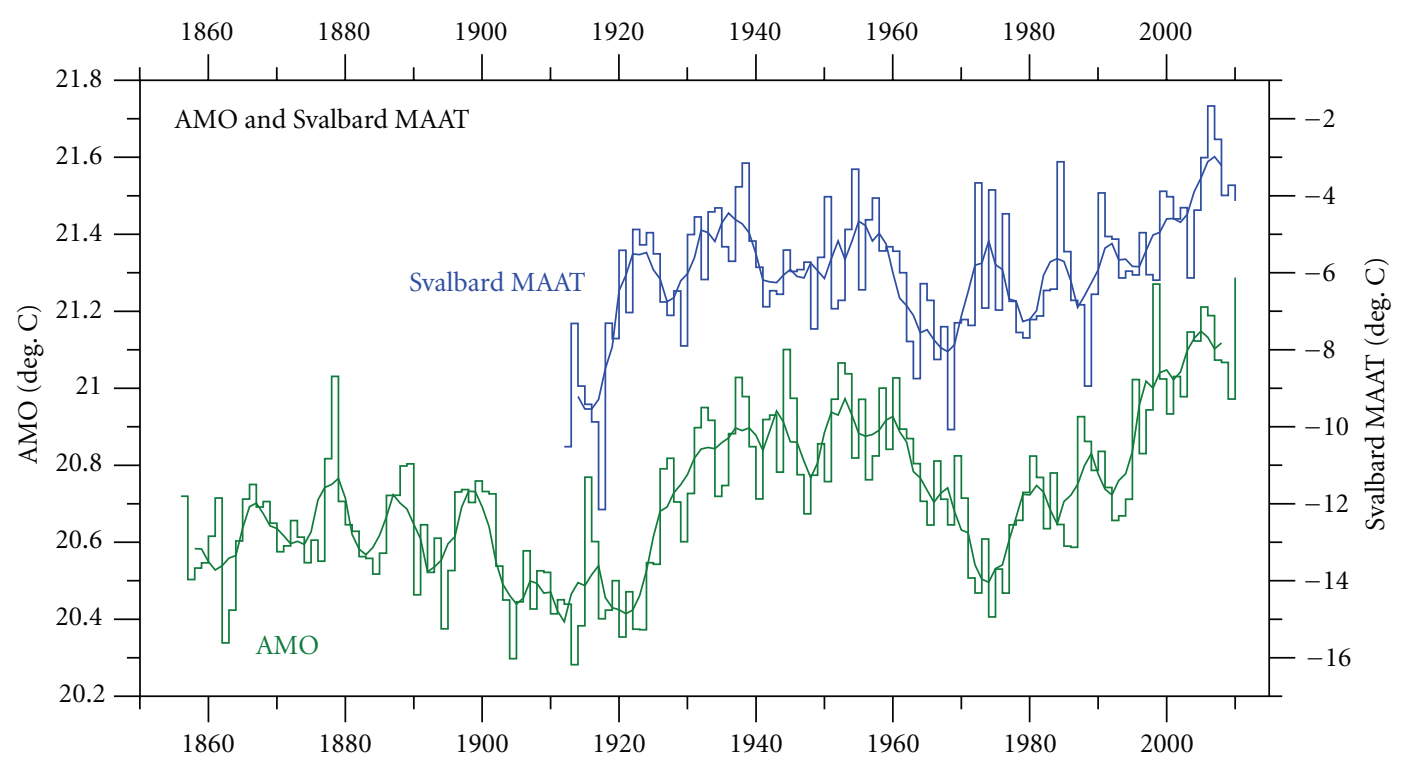

FIgure 4: Svalbard MAAT 1912-2010 (blue) and Atlantic Multidecadal Oscillation (AMO, green) annual index values 1856-2010. The thick lines are the simple running 5 year average. Note that the temperature scales are different.

and 16.8-16.7 yr periods may possibly represent sub-harmonics of the about $8.8 \mathrm{yr}$ period.

5.1. Potential Physical Controls on the Observed Cycles. A physical explanation may be suggested for some of the cycles identified, as discussed in some detail by Humlum et al. [4]. The precession of both the Moon's orbital nodes and the Earth's nutation has an approximate period of $18.6 \mathrm{yr}$. By causing small accelerations and decelerations of the tidal bulges moving around Earth, this may cause small changes in ocean currents transporting heat towards high latitudes, for example, in the North Atlantic. The resulting variations in sea surface temperature might then influence the temperature of the atmosphere above the oceans (Keeling and Whorf [27]), whereby there may be a potential link between orbital variations of the Moon and the MAAT recorded at meteorological stations located near a major ocean, such as the meteorological station at Svalbard Airport.

Orbital variations of the Moon and the Earth have since long been suggested to influence upon long-period ocean tides, climate cycles, and variations of marine biomasses (Pettersson [28-31]). Later Maksimov and Smirnov [32] and Currie [33-35] analysed surface temperatures in the North Atlantic and found temperature cycles close to the $18.6 \mathrm{yr}$ lunar nodal cycle. In addition, the $18.6 \mathrm{yr}$ nodal tide has a poleward velocity component [36] and amplitude of approximately $7 \%$ of the lunar diurnal component [37], which may influence the ocean surface layer and air temperatures at high latitudes (Royer [38]; Keeling and Whorf [27]). Yndestad [39-41] actually was able to identify harmonic and sub-harmonic lunar nodal cycles of 18.6/3= $6.2 \mathrm{yr}, 18.6,3 \times 18.6=55.8 \mathrm{yr}$, and $4 \times 18.6=74.4 \mathrm{yr}$ in temperature series from the Barents Sea between mainland Norway and Svalbard.

The $62,37-36,26,16.8$, and $8.8 \mathrm{yr}$ periods identified by the wavelet analysis (Figure 3 ) may potentially all be interpreted as lunar signals. The $8.8 \mathrm{yr}$ period is very close to the fundamental $8.8504 \mathrm{yr}$ lunar period, also known as the period of recession of line of apsides, and the longer periods may represent subharmonics of this fundamental period. On the other hand, this does not have to be so, and some of these periods may represent oscillations in their own rights. As one example, the $62 \mathrm{yr}$ period is known from other records (e.g., [6]), and an about $60 \mathrm{yr}$ long period has also been found in the movement of the barycentre of the solar system [42].

The similarity between the identified Svalbard $62 \mathrm{yr}$ MAAT period and the variation of the Atlantic Multidecadal Oscillation (AMO, [43]) should also be noted (Figure 4). AMO is a mode of variability occurring in the North Atlantic Ocean sea surface temperature field and basically represents an index of North Atlantic sea surface temperatures (SST). This similarity also applies to the overall changes of MAAT during the observational period, emphasising the influence of Atlantic sea surface temperatures on air temperature recorded in Svalbard.

The longer $83 \mathrm{yr}$ period may correspond to the solar Gleissberg cycle (named after Wolfgang Gleißberg), ranging from 50 to $140 \mathrm{yr}$, with a maximum around $88 \mathrm{yr}$ [44], corresponding to four times the Hale cycle of $22 \mathrm{yr}$. However, given the limited length ( $98 \mathrm{yr}$ ) of the Svalbard MAAT data series, this long oscillation is located entirely in the cone of influence and its apparent presence should therefore not be interpreted in too much detail.

Thus, both lunar and solar signals may be present in the Svalbard record. Most of the cycles identified longer than $15 \mathrm{yr}$ appear to have an almost stationary cycle length and stationary signal magnitude, while the shorter cycles are less stable and tend to come and go with time (Figure 3 ). More work on this is needed, but it remains a possibility that these short and not very strong oscillations should be considered as noise only. Indeed, the Fourier analysis (Figure 2 ) suggests that this might be the case. However, several of 


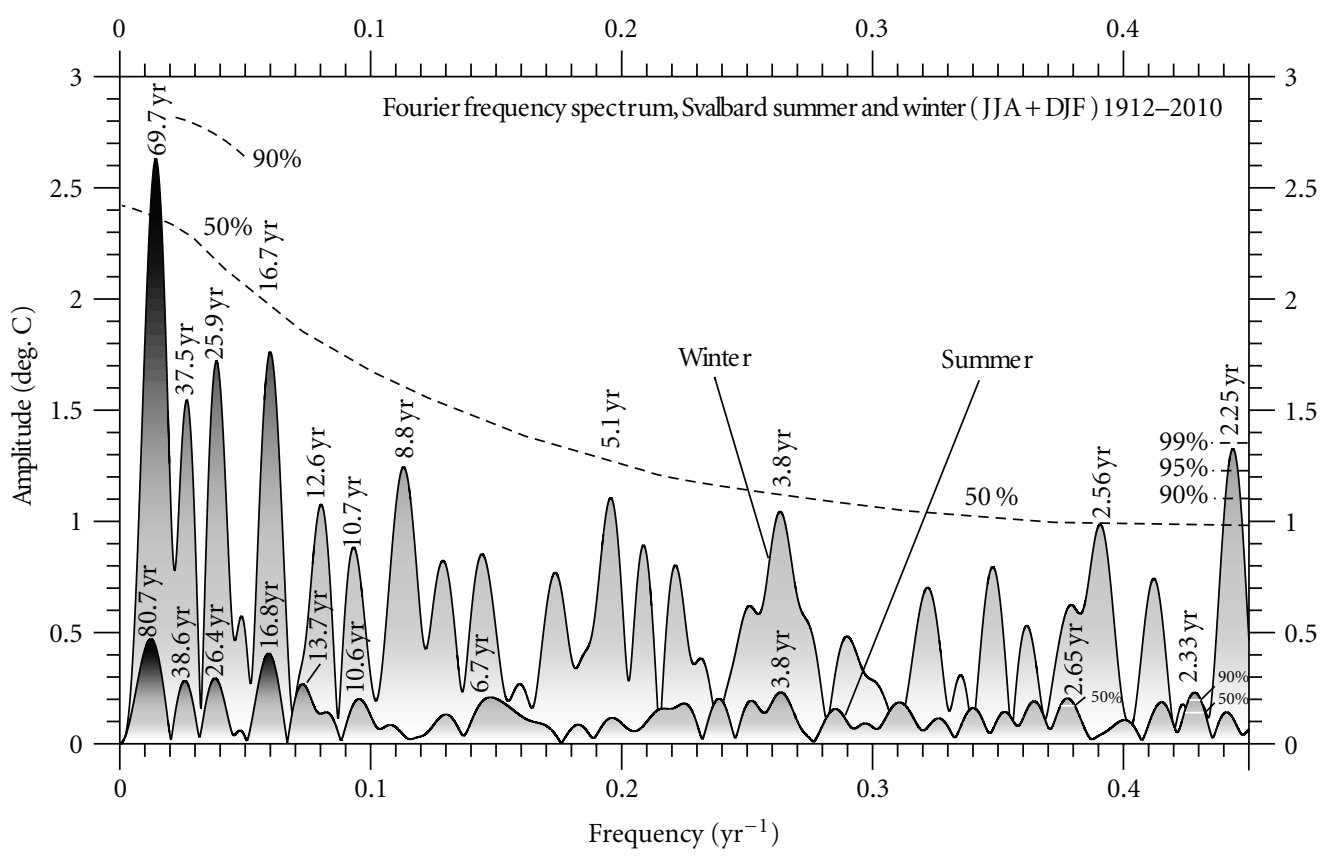

Figure 5: Fourier analysis (using Best Exact N composite algorithm) of the detrended Svalbard 1912-2010 winter (DJF) and summer (JJA) series. The amplitude of the winter signal is larger than the summer signal. The winter record is dominated by three periods of about 69.7 , 25.9 and $16.7 \mathrm{yr}$ length, all with amplitude greater than $1.7^{\circ} \mathrm{C}$. The summer record is dominated by three periods of about $80.7,26.4,16.8$, and $13.7 \mathrm{yr}$ length, all with amplitude about $0.3^{\circ} \mathrm{C}$ or higher. The grey tone indicates increasing amplitude within each record. The stippled

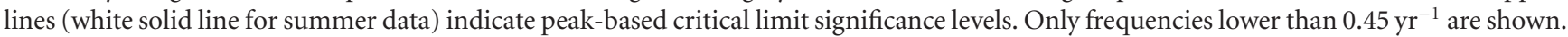

the stronger periods identified in the Svalbard MAAT record resemble similar periods observed in Barents Sea surface temperatures (Yndestad [39-41]), again emphasising that air temperatures in Svalbard probably are strongly influenced by oceanographic and sea ice conditions (see, e.g., Benestad et al. [45]), and that these periods are real phenomenon, worthy of analysis.

\section{The Svalbard Winter and Summer Temperature Record Compared}

Figure 1 show clear differences between the Svalbard summer (JJA) and winter (DJF) air temperature, especially as to their variability. Figure 5 shows the result of Fourier analyses of these two data series, after removing 1912-2010 linear decadal trends of $0.25^{\circ} \mathrm{C}(\mathrm{DJF})$ and $0.10^{\circ} \mathrm{C}(\mathrm{JJA})$, respectively.

The Svalbard winter record is seen to be dominated by three periods of about $69.7,25.9$, and $16.7 \mathrm{yr}$ length, all with amplitude greater than $1.7^{\circ} \mathrm{C}$, much like what was the case for the MAAT record, reflecting the importance of winter temperatures for the MAAT. The $69.7 \mathrm{yr}$ peak is close to the $75 \%$ critical limit, indicating that in only 1 of 4 separate random noise signals the highest peak would achieve this height strictly due to random chance. However, in a statistical sense the about $2.25 \mathrm{yr}$ oscillation (amplitude about $1.3^{\circ} \mathrm{C}$ ) is by far the most significant, almost reaching the $99 \%$ critical limit. This explains why seldom more than two very cold or warm winters in a row occur in Svalbard.
The summer record (lower graph in Figure 5) is dominated by two periods of 80.7 and $16.8 \mathrm{yr}$, both with amplitude exceeding $0.4^{\circ} \mathrm{C}$. Two additional periods, 26.4 and $13.7 \mathrm{yr}$, reach peak amplitude values about $0.3^{\circ} \mathrm{C}$. The most statistical significant period is the $2.33 \mathrm{yr}$ oscillation, which however has small amplitude only, about $0.2^{\circ} \mathrm{C}$. This demonstrates that it is possible for a statistically significant factor to be of little practical importance, and vice versa.

Thus, according to the Fourier spectral analysis, there are both similarities and differences between Svalbard winter and summer temperatures 1912-2010. However, we feel encouraged by the overall degree of similarity in the spectra of the winter and summer series. The autoregressive value was found to be somewhat higher for the summer data $\left(\operatorname{AR}(1)_{\text {summer }}=0.47\right)$ than for the winter data $\left(\operatorname{AR}(1)_{\text {winter }}=0.43\right)$. In general the winter temperature amplitudes are much larger than the summer amplitudes, and the discrepancy as to frequency of winter and summer oscillations are seen to increase with increasing frequency, presumably again reflecting that periodic oscillations shorter than $15 \mathrm{yr}$ come and go, while longer oscillations tend to be more persistent. However, at the same time it should be borne in mind that the ability of determining oscillations decreases with increasing period length.

Figure 6 shows the result of wavelet analyses of the Svalbard winter and summer temperature record. The strong signal magnitude of the winter record (upper diagram) is apparent when compared to the summer record (lower diagram). Since 1912 four dominant periods of about 83, 
Svalbard winter (DJF) 1912-2010 wavelet analysis morlet complex Adj10 $N_{\min } 250$

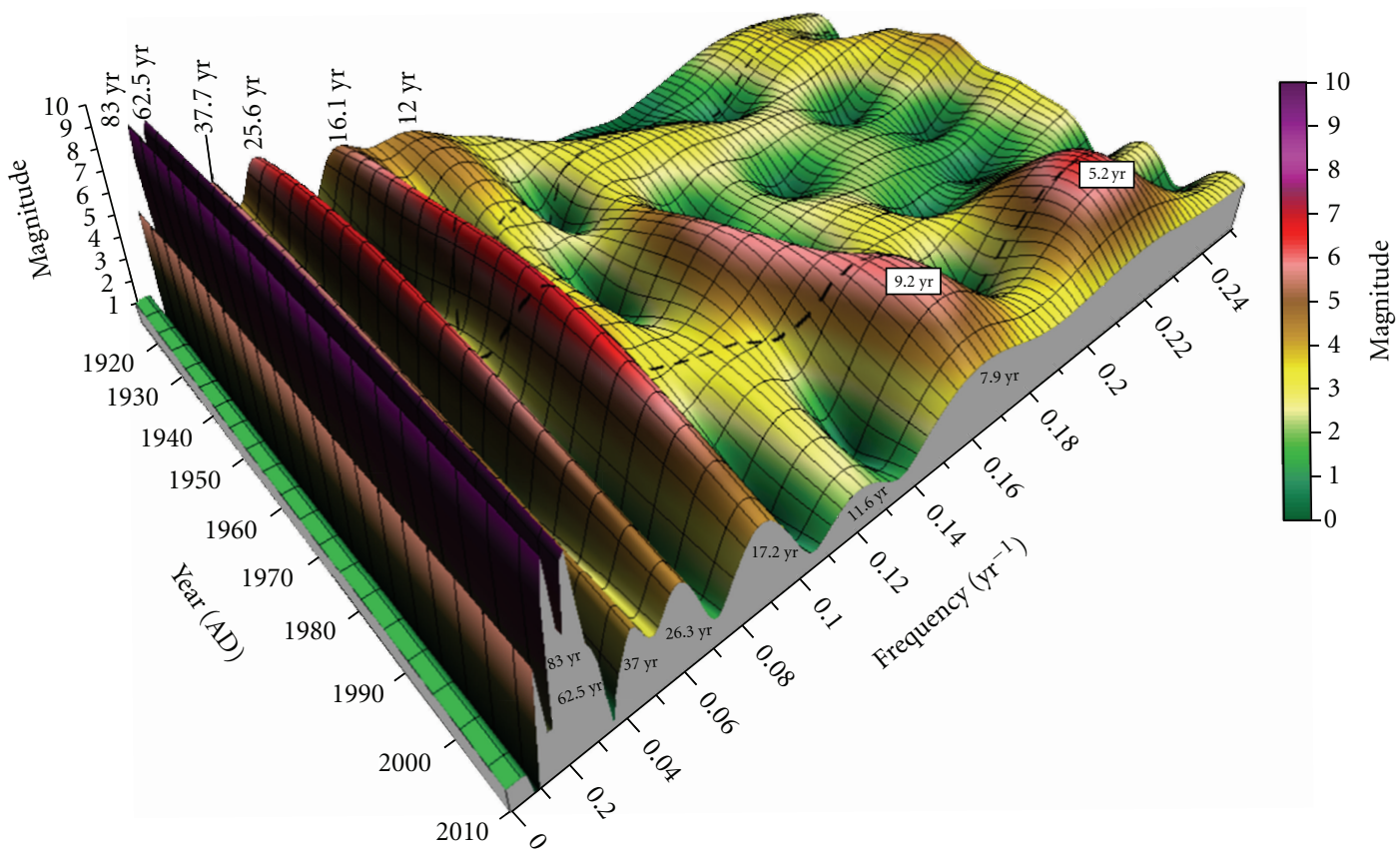

(a)

Svalbard summer (JJA) 1912-2010 wavelet analysis morlet complex Adj10 $N_{\min } 250$

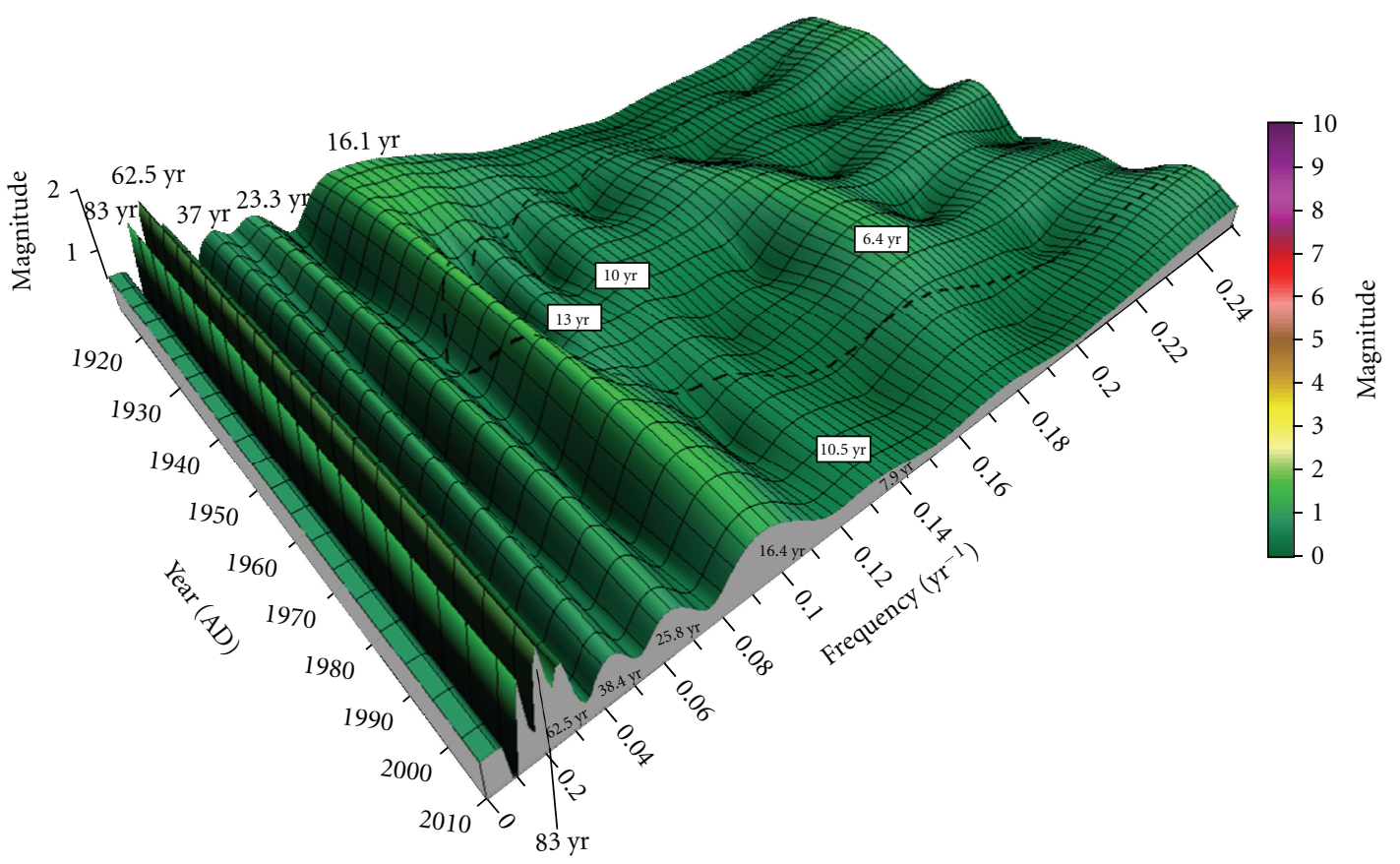

(b)

FIGURE 6: Diagrams showing the continuous wavelet time-frequency spectrum for the Svalbard winter (DJF) and summer (JJA) temperature series 1912-2010. The time (AD) and frequency $\left(\mathrm{yr}^{-1}\right)$ of cyclic variations embedded in the temperature data shown along the horizontal axes. Frequencies higher than $0.25 \mathrm{yr}^{-1}$ are not shown, corresponding to showing only periods longer than $4 \mathrm{yr}$. The vertical axis (and colour scale) shows the magnitude of the Continuous Wavelet Spectrum at a given time and frequency. The magnitude is calculated as sqrt(Re* $\operatorname{Re}$ $+\operatorname{Im} * \operatorname{Im})$, where Re is the real component of a given segment's FFT at a given frequency and Im is the imaginary component. Usually the magnitude is 3-4 times the corresponding amplitude. The dotted line indicates the extent of the cone of influence. Identical colour scales have been used for both diagrams to emphasise the winter-summer difference as to signal magnitude. The winter data shows the edge effect of zero padding, see, for example, the 5.2 and $9.2 \mathrm{yr}$ oscillations. 
$62.5,25.6-26.3$, and $16.1-17.2 \mathrm{yr}$ characterise the winter record. Weaker 11.9-12 and 7.9-9.2 yr periods are also present. The summer record is dominated by $83,62.5,25.3-$ 25.8 , and $16.1-16.4 \mathrm{yr}$ periods. From a spectral point of view, the similarity between the two seasonal records is striking, especially for oscillations longer than about $10 \mathrm{yr}$, although the magnitude of the seasonal signals is very different. The colour scale is identical for the two diagrams, emphasising the difference as to signal magnitude. It is also seen that while all four main periods are strong, the about 26 and 16-17 yr oscillations are changing towards somewhat smaller influence in recent years. A weaker oscillation of about 37$38 \mathrm{yr}$ is visible in both seasonal records, but with reduced influence in recent years. All these relatively long periods have been relatively stable over the entire 1912-2010 time range with regard to both magnitude and frequency, even within the cone of influence, where spectral powers may be artificially diminished because of zero padding.

The fact that the result of the seasonal analyses resembles the result of the MAAT record suggests the oscillations identified to be real features and not just noise or artefacts derived from the averaging procedure used to produce the annual record. The fact that other North Atlantic temperature records display similar oscillations (Humlum et al. [26]) lends support to this notion. We therefore feel confident that these oscillations most likely represent phenomena worthy of analysis.

During summer the daily meteorological conditions are highly influenced by the incoming solar radiation, which at $78^{\circ} 13^{\prime} \mathrm{N}$ are continuously above the horizon from 19 April to 23 August. Nevertheless, because of the nearby ocean, the air temperature usually stays relatively low, with July having an average temperature of $6.5^{\circ} \mathrm{C}(1981-2010)$. Summer air temperatures are also influenced by local wind conditions, partly reflecting land-sea breeze effects because of relatively small regional air pressure differences during the summer. All these factors are relatively stable from summer to summer.

During winter the meteorological conditions are very different from the summer. The sun stays below the horizon from 28 October to 14 February, and there is very little incoming solar radiation from December to February. The ground is snow covered, and much of the surrounding ocean and fjords are covered by sea ice. So whenever calm conditions prevail, inversions tend to develop and temperatures will be low at Svalbard Airport. However, conditions are frequently windy during the winter, destroying inversions, and from time to time warm air masses are advected towards Svalbard from the North Atlantic. Whenever this happens, the air temperature will rise significantly, as much as 10 $15^{\circ} \mathrm{C}$ within few hours. In winters with high frequency of such events, the average temperature will be high and vice versa in winters where advection of warm air masses occurs less often. Also local foehn effects may be important during the winter. Together, this explains the high degree of winter temperature variability compared to the summer variability.

Advection of warm air masses from lower latitudes towards Svalbard occurs at all seasons, but is most frequent during the winter. This explains why the Svalbard air temperature is well coupled to North Atlantic temperature conditions both in summer and winter, and why several oscillations can be recognised in the spectra of both summer and winter temperature records (Figure 5). Had this not be so, one would expect at least potential solar signals to be absent from the winter data.

The 62, 37-36, 26, and 16-17yr periods identified by the wavelet analysis in the winter and summer record (Figure 6) may potentially be interpreted as lunar signals. In addition, the $62 \mathrm{yr}$ period may be directly linked to the AMO [43], an index for Atlantic surface temperatures. The shorter 7.9-9.2 yr period visible in the winter record is close to the fundamental $8.8504 \mathrm{yr}$ lunar period, and the above-mentioned longer periods may possibly represent subharmonics of this. However, as discussed above, some of these longer periods may represent oscillations in their own rights, as they also appear in other types of environmental records. As one example, the long 83 yr period visible in both Svalbard seasonal records may possibly correspond to the solar Gleissberg cycle [44].

Thus, when considering summer and winter periodic variations identified in the entire 98 yr Svalbard temperature record, oceanographic, lunar, and solar signals all appear potentially to be present. Most of the cycles identified longer than $15 \mathrm{yr}$ appear to have almost stationary cycle length and magnitude, while the shorter cycles tend to come and go with time. However, our main purpose here is not the physical interpretation of the various oscillations, and a more thorough analysis would probably require an analysis of simultaneous wind strength and direction data.

\section{Modelling the Svalbard MAAT Record 1912-1990}

As the above wavelet analyses show most of the dominant oscillations to be stationary or quasistationary phenomena, it is feasible to construct a harmonic or sinusoidal model approximating the original data. Here we choose to focus on the Svalbard MAAT record only, investigating both hindcasting and forecasting ability of such a modelling approach, again building on a previous analysis [4].

The algorithm used for our modelling attempt was obtained by a nonlinear optimization procedure, described in [4]. As some of the individual periods are slowly changing with time (Figure 3 ), the chosen sinusoids had to be optimized for frequencies, amplitudes, and phases for the entire period investigated, and they may therefore differ somewhat from both the modern situation and the result of the Fourier analysis (Figure 2). However, when the strongest cyclic variations are relatively stable, as demonstrated by the wavelet analysis to be the case for the Svalbard MAAT record, this does not represent a major problem for the construction of a harmonic model. The coefficient of determination $\left(r^{2}\right)$ along with the sample size $(N)$ represents a guide for the degree of success of the model optimization.

When carrying out the nonlinear optimization to construct a harmonic or sinusoidal model approximating the original data, it is in principle possible to incorporate any number of periodic variations identified by the wavelet 
analysis (Figure 3). However, to keep the analysis simple and by this demonstrate the value of our approach, we decided to take into account only three important periodic variations, as the wavelet analysis suggested a relatively low number of dominant periodic variations to describe the overall features of the record. Had we instead chosen to incorporate a higher number of periodic variations, the hindcasting ability of our model would improve, but using a sufficient high number of variations anything may be modelled. However, here our main purpose is to demonstrate that a low number (three) of periodic variations apparently explain all main features of the Svalbard temperature record. The resulting modelled data series was finally retrended to produce a hindcast comparable to the real Svalbard MAAT 1912-1990 (Figure 7).

To investigate the length of the realistic forecasting time range, if any, we next conducted a series of out-of sample tests where the Svalbard MAAT series was truncated stepwise back in time from the last year in the record (2010). From the truncated series we generated forecasts for the period between the year of truncation and 2010, to compare with known data for this period. By this it turned out that we could still produce useful forecast until 2010 when truncating as early as 1990. The nonlinear optimization for the truncated 1912-1990 data series resulted in a optimized model combining three periods of $71.7,24.9$, and 15.3 yrs. By this the original data were hindcasted with a coefficient of determination $r^{2}=0.36(N=78)$. For comparison, a linear regression of the same data yielded a coefficient of determination $\left(r^{2}\right)$ of only 0.02 .

Our three-period-only model reproduces all main features displayed by the Svalbard 1912-1990 record (Figure 7), including the rapid early 20th century warming 1917-1922, the warm peak 1930-1940, and another warm period centred on 1955-1957, the subsequent cold period culminating 1967-1968, and increasing temperatures from then until around 2006. In other words, had we made this forecast back in 1991, the now observed temperature peak 2005-2007 could have been forecasted, even though in 1991 there were no indications for such a future development.

The forecasted 1991-2010 period represents about 26\% of the length of the truncated 1912-1990 Svalbard series. We investigated the distribution of annual model errors (model minus measured MAAT) and found no change in the error distribution and its magnitude at the truncation year 1990. Errors 1991-2010 remain essentially identically to those characterising the previous period 1912-1990, with random distribution between positive and negative values. This demonstrates that our simple three-period-only model manages to stay on track in relation to the observed data for the whole period, both before and after 1990. The typical annual model error is $1-4^{\circ} \mathrm{C}$, which for the individual year is a considerable error. Obviously our model should not be tested (falsified) within such a short-time period, but over several years. The fit between modelled values and the simple moving $9 \mathrm{yr}$ average suggests a forecasting falsification time range of about 9 years for our simple 1912-1990 threeperiod-only model.

More work on the useful forecasting time range for this approach is clearly needed. However, our preliminary experience from undertaking out-of-sample tests like the above on several other meteorological series suggests the useful forecasting time range to be $10-25 \%$ of the length of the background data series. Time series where the dominant periods vary with regard to length and strength obviously have a relatively short forecasting time range, while series characterised by more stable dominant periods (like the Svalbard series) have longer forecasting time ranges.

\section{Modelling and Forecasting Using the Svalbard MAAT Record 1912-2010}

We next developed an optimized model for the entire 1912-2010 observational period, still using only three input periods. This resulted in a model combining periods of $74.3,24.5$, and $17.1 \mathrm{yr}$ (see Table 1 for listing of periods), by which the original data were hindcasted with a coefficient of determination $r^{2}=0.47(N=98)$. For comparison, a linear regression of the same data yielded a coefficient of determination $\left(r^{2}\right)$ of 0.14 . It may be noted that the $74.3 \mathrm{yr}$ period found and used by the optimized model might be seen as related to the fundamental $18.6 \mathrm{yr}$ lunar period $(4 \times$ $18.6=74.4 \mathrm{yr}$ ), and that the $24.5 \mathrm{yr}$ period is identical to a third harmonic cycle of the $74.4 \mathrm{yr}$ cycle $(74.4 / 3=24.5 \mathrm{yr})$. The $17.1 \mathrm{yr}$ model period is close to the $16.9-16.7 \mathrm{yr}$ period found by the wavelet analysis (Figure 3 ). In principle, even the best optimized model may yield results without real physical meaning, but, in our opinion, when it is possible to relate known physical phenomena to the results this lends support to the value of the model.

From Figure 8 it is seen that our three-period-only optimized model reproduces all main features displayed by the Svalbard MAAT record, including the rapid early 20th century warming 1917-1922, the warm peak 1930-1940, another warm period centred on 1955-1957, the subsequent cold period peaking 1967-1968, a warm period 1970-1975, a cold period around 1980, and finally the subsequent warming until 2006/2007.

Annual model errors are typically $1-3^{\circ} \mathrm{C}$. The somewhat smaller error margin compared to the 1912-1990 analysis is due to the longer data set and improved determination of dominant oscillations. The spread of annual errors is seen to be random and does not show a trend towards dominance of either positive or negative values, demonstrating that our simple three-period model stays on track for the entire record. The wavelet analyses (Figures 3 and 6) suggests the dominant variations in the record to be stable with respect to both strength and magnitude. This suggests that variations which are strong now are likely to continue without major changes at least some time into the future, and therefore likely to influence the future Svalbard MAAT. Based on the optimized 1912-2010 model we therefore generated a forecast of Svalbard MAAT until 2035, as shown in the righthand part of Figure 8 . This represents about $25 \%$ of the original data series length.

Our forecast suggests future MAAT in Svalbard to decline until around 2015-2017, to be followed by a new warming period, peaking around 2026. Following this future 


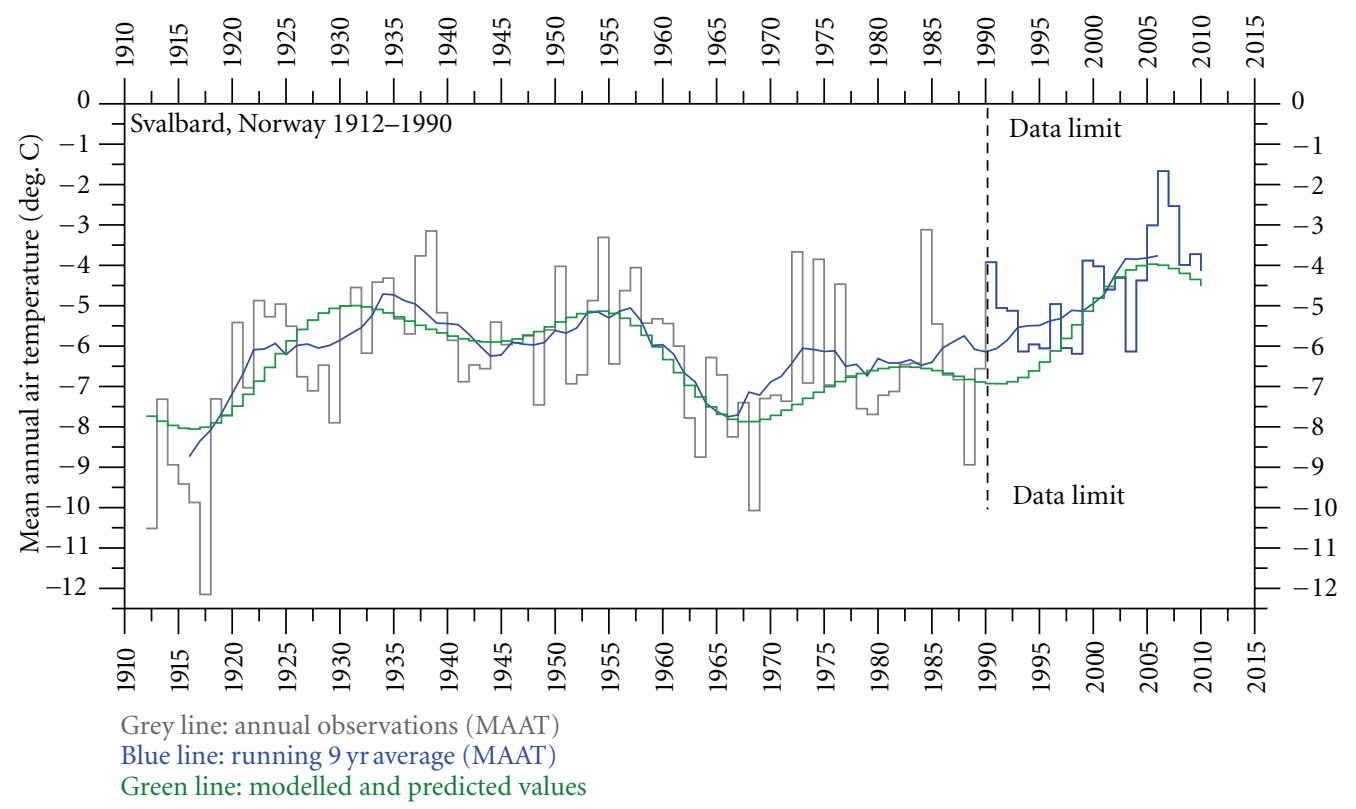

FIGURE 7: The truncated Svalbard MAAT series 1912-1990, redrawn from [4]. The grey line shows annual observed values. The thin blue line shows the measured values 1991-2010, which were excluded from analysis. The thick blue line shows the simple running $9 \mathrm{yr}$ average of the original data. MAAT values modelled using three cycles only are shown by the green line. The 1991-2010 part of this represents the out-of-sample forecast. The coefficient of determination $\left(r^{2}\right)$ for the hindcasting period is $0.36(N=78)$. The overall linear temperature trend $1912-1990$ is $0.099^{\circ} \mathrm{C}$ per decade, and this overall trend is assumed to continue beyond 1990 when plotting the forecasted data.

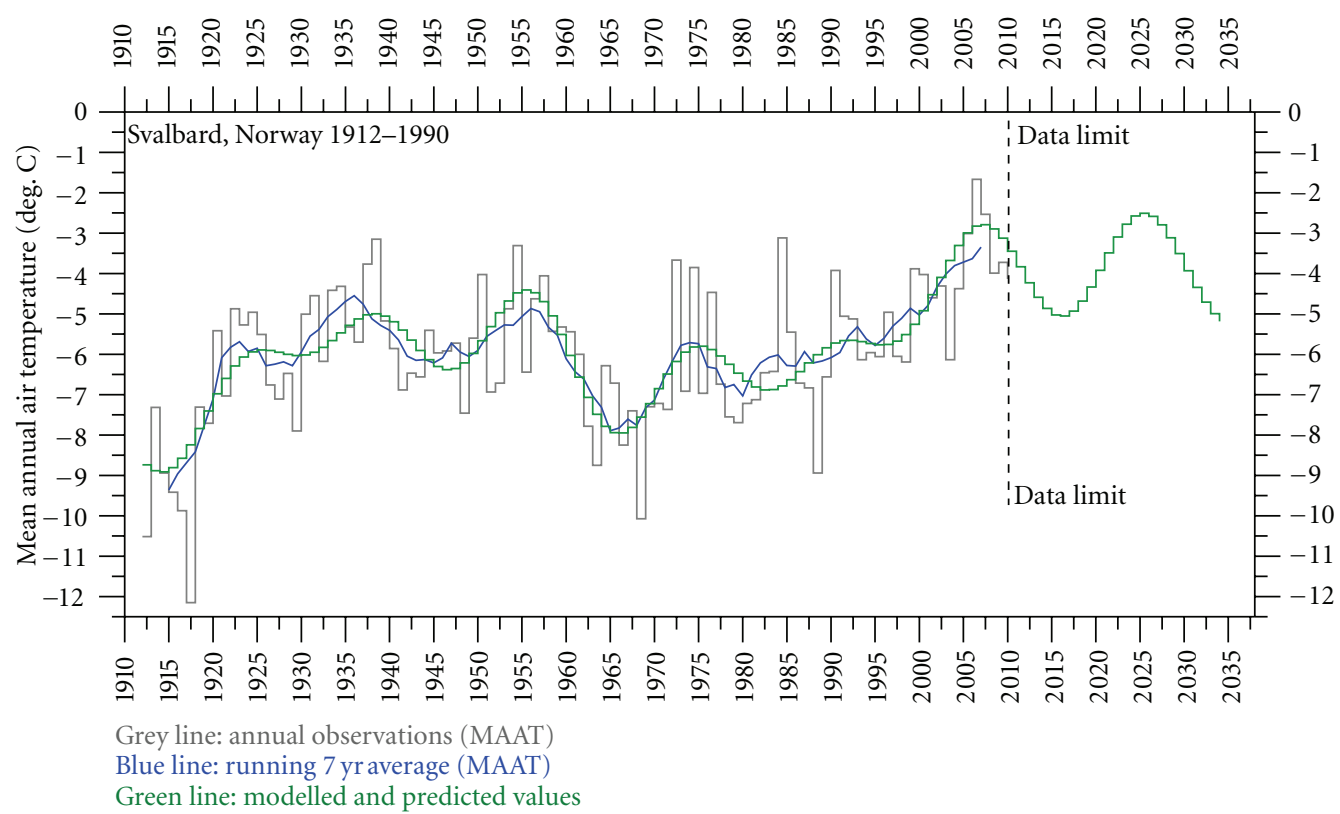

Figure 8: The Svalbard MAAT series 1912-2010, redrawn from [4]. The grey line shows annual values, and the blue line shows the simple running $7 \mathrm{yr}$ average of these original data. MAAT values modelled from three cycles only are shown by the green line. The coefficient of determination $\left(r^{2}\right)$ for the hindcasting period is $0.47(N=98)$. The linear temperature trend $1912-2010$ is $0.23^{\circ} \mathrm{C}$ per decade. This overall trend is assumed to continue beyond 2010 when plotting the forecasted data. As mentioned above, this trend may be unrealisticly high, being influenced by the data series starting at a low and ending at a high value.

temperature peak MAAT again is forecasted to decline. As mentioned previously, our forecast may be influenced by an unrealistic high linear trend 1912-2010. Should the real overall trend be lower, which we consider likely, this would change our forecast towards correspondingly lower temperatures than shown in Figure 7. As our model hindcast 1912-2010 (Figure 8) is close to the moving simple $7 \mathrm{yr}$ average, we suggest a falsification time scale of about 7 years. Incorporating additional periods in the model would produce a more detailed forecast and a somewhat shorter 
TABLE 1: Length of cyclic variations found in the Svalbard 1912-2010 MAAT record by Fourier and wavelet analysis, and period length used for reproducing the MAAT 1912-1990 and 1912-2010 MAAT record with only three input periods, respectively. Parentheses around Fourier values indicate that these variations may possibly represent harmonics of the longer $68.4 \mathrm{yr}$ variation. Italic columns indicate periods used in the models (Figures 7 and 8).

\begin{tabular}{|c|c|c|c|c|c|c|c|c|}
\hline Cycle length & $80-100$ & $50-79$ & $30-49$ & $20-29$ & $15-19$ & $11-14$ & $9-11$ & $8-9$ \\
\hline Fourier analysis & & 68.4 & $(36.7)$ & 25.7 & 16.8 & $(12.3)$ & 10.5 & 8.7 \\
\hline Wavelet & 83 & 62 & 36 & 26 & $16.8-16.7$ & $12.5-11.6$ & & 8.8 \\
\hline Model 1912-1990 & & 71.7 & & 24.9 & 15.3 & & & \\
\hline Model 1912-2010 & & 74.3 & & 24.5 & 17.1 & & & \\
\hline
\end{tabular}

falsification time range, but here our aim is to demonstrate that all main features of the Svalbard temperature record may be reproduced by combining a low number of periodic variations only. Table 1 shows all the main periods found or used in the above analysis of the Svalbard MAAT record.

Solheim et al. [46] uses a model based on the empirical relation between solar cycle length and Svalbard MAAT to forecast temperatures in the Svalbard region the coming decade. This analysis is entirely different from the approach used in the present paper, but also results in a forecast of overall decreasing temperatures during the next decade, in concert with the forecast presented here. This agreement lends support to our interpretation that some of the oscillations identified in the Svalbard temperature record may be derived from solar variations, and that the oscillations identified in the present paper are real phenomena worthy of analysis, even though their statistical level of significance may appear relatively low when seen in isolation from other records.

\section{Conclusions}

(1) This study has identified persistent cyclic variations in the Svalbard temperature record. These oscillations are also found when considering seasonal data (summer and winter), supporting the notion that the oscillations are real features, even though their statistical significance is relatively low.

(2) Some of the identified cycles appear to correspond to known cyclic variations in the Moons' orbit around Earth, while others may reflect solar variations.

(3) Natural cycles that have remained strong over long time are likely to continue without major changes into at the near future. Knowledge on such natural oscillations is therefore essential for forecasting future climate. Forecasts based on Fourier and wavelet analysis should therefore not be considered purely statistical, as they are based on observed dynamics characterising past climate change.

(4) Strength and persistence of several cyclic variations identified in the Svalbard temperature record suggests that a natural cycle-based forecasting of future climate may be feasible for the Svalbard record, at least for a limited time ranges. Our empirical exper- ience suggests a forecasting time range of $10-25 \%$ of the total record length.

(5) For Svalbard our experimental forecast suggests that the observed late 20th century warming is not going to continue, but are likely to be followed by variable, but generally not higher temperatures for at least the coming 20-25 years. The falsification time scale for this forecast is about 7 years.

(6) The natural cycle climate model forecast described in the present paper is seen as supplementary to projections derived from analytic climate models, and thereby represents a complimentary approach to climate forecasting based on such analytic models.

\section{Acknowledgments}

The present study was carried out partly at the University of Oslo, and partly at the University Centre in Svalbard (UNIS). The Wavelets package AutoSignal v.1.7 by SeaSolve Software Inc, was used for data analysis. The Svalbard temperature data series used was obtained from the eKlima Internet data portal run by the Norwegian Meteorological Institute. The paper benefited considerably from the comments of an anonymous referee.

\section{References}

[1] R. B. Braithwaite, Scientific Explanation, Harper Torch, New York, NY, USA, 2nd edition, 1960.

[2] K. Faegri, "On the value of palaeoclimatological evidence," in Proceedings of the Royal Meteorological Society, Centenary Proceedings, pp. 87-95, 1950.

[3] I. I. Schell, D. A. Corkum, and E. N. Sabbagh, "Recent climatic changes in the Eastern North American sub-arctic," in Proceedings of the 24th Alaska Science Conference, Climate of the Arctic, G. Weller and S. A. Bowling, Eds., pp. 76-81, Fairbanks, Alaska, USA, August 1973.

[4] O. Humlum, J.-E. Solheim, and K. Stordahl, "Identifying natural contributions to late Holocene climate change," Global and Planetary Change, vol. 79, no. 1-2, pp. 145-156, 2011.

[5] S. Solomon, K. H. Rosenlof, R. W. Portmann et al., "Contributions of stratospheric water vapor to decadal changes in the rate of global warming," Science, vol. 327, no. 5970, pp. 12191223, 2010.

[6] L. B. Klyashtorin and A. A. Lyubushin, Cyclic Climate Changes and Fish Productivity, Vniro Publishing, Moscow, Russia, 2007. 
[7] I. Polyak, Computational Statistics in Climatology, Oxford University Press, Oxford, UK, 1996.

[8] H. W. Ahlmann, Glacier Variations and Climatic Fluctuations, Bowman Memorial Lectures, American Geographical Society, New York, NY, USA, 1953.

[9] H. H. Lamb, Climate, Present, Past and Future, Climatic History and the Future, vol. 2, Methuen and Co, London, UK, 1977.

[10] J. C. Rogers, L. Yang, and L. Li, "The role of Fram Strait winter cyclones on sea ice flux and on Spitsbergen air temperatures," Geophysical Research Letters, vol. 32, no. 6, Article ID L06709, 4 pages, 2005.

[11] J. T. Houghton, Y. Ding, D. J. Griggs et al., "Climate change 2001: the scientific basis," in Proceedings of the Contribution of Working Group I to the 3rd Assessment Report of the Intergovernmental Panel on Climate Change, Cambridge University Press, 2001.

[12] E. J. Førland, I. Hanssen-Bauer, and P. Ø. Nordli, "Climate statistics \& longterm series of temperature and precipitation at Svalbard and Jan Mayen," Tech. Rep. 21/97 klima, Det Norske Meteorologiske Institutt, 1997.

[13] I. Hanssen-Bauer, M. Kristensen Solås, and E. L. Steffensen, "The climate of Spitsbergen," Tech. Rep. 39/90, The Norwegian Meteorological Institute, 1990.

[14] P. Ø. Nordli, I. Hanssen-Bauer, and E. Førland, "Homogeneity analyses of temperature and precipitation series from Svalbard and Jan Mayen," Tech. Rep. 16/96, The Norwegian Meteorological Institute, 1996.

[15] H. Alexandersson, "A homogeneity test applied to precipitation data," Journal of Climatology, vol. 6, no. 6, pp. 661-675, 1986.

[16] I. Hanssen-Bauer and E. J. Forland, "Homogenizing long Norwegian precipitation series," Journal of Climate, vol. 7, no. 6, pp. 1001-1013, 1994.

[17] J. Morlet, Sampling Theory and Wave Propagation, NATO ASI Series, Vol Fl, Springer, 1983.

[18] C. Torrence and G. P. Compo, "A practical guide to wavelet analysis," Bulletin of the American Meteorological Society, vol. 79, no. 1, pp. 61-78, 1998.

[19] K.-M. Lau and H. Weng, "Climate signal detection using wavelet transform: how to make a time series sing," Bulletin of the American Meteorological Society, vol. 76, no. 12, pp. 23912402, 1995.

[20] S. Baliunas, P. Frick, D. Sokoloff, and W. Soon, "Time scales and trends in the Central England temperature data (16591990): a wavelet analysis," Geophysical Research Letters, vol. 24, no. 11, pp. 1351-1354, 1997.

[21] E. Isaksson, D. Divine, J. Kohler et al., "Climate oscillations as recorded in Svalbard ice core $\mathrm{d} 18 \mathrm{O}$ records between $\mathrm{AD}$ 1200 and 1997," Geografiska Annaler, Series A, vol. 87, no. 1, pp. 203-214, 2005.

[22] C. J. Butler, A. García-Suárez, and E. Pallé, “Trends and cycles in long Irish meteorological series," Proceedings of the Royal Irish Academy Biology and Environment, vol. 107, no. 3, pp. 157-165, 2007.

[23] P. Chylek, C. K. Folland, H. A. Dijkstra, G. Lesins, and M. K. Dubey, "Ice-core data evidence for a prominent near 20 year time-scale of the Atlantic Multidecadal Oscillation," Geophysical Research Letters, vol. 38, no. 13, Article ID L13704, 2011.

[24] C. E. Shannon, "Communication in the presence of noise," Proceedings of the Institute of Radio Engineers, vol. 37, no. 1, pp. 10-21, 1949.

[25] SeaSolve, AutoSignal. Pioneering Automated Signal Analysis and Advanced Filtering. User's Manual, SeaSolve Software, Framingham, Mass, USA, 2003.
[26] O. Humlum, J.-E. Solheim, and K. Stordahl, "Identifying natural oscillations in North Atlantic temperature records," In press.

[27] C. D. Keeling and T. P. Whorf, "Possible forcing of global temperature by the oceanic tides," Proceedings of the National Academy of Sciences of the United States of America, vol. 94, no. 16, pp. 8321-8328, 1997.

[28] O. Pettersson, "On the probable occurrence in the Atlantic current of variations periodical, and otherwise, and their bearing on metrological and biological phenomena," Rapports et Procès-Verbaux des Réunions de Conseil Permanent International pour l'Exploration de la Mer, vol. 42, pp. 221-240, 1905.

[29] O. Pettersson, "Climatic variations in historic (sic) and prehistoric time," in Svenska Hydrografisk Biologiska Kommissionens Skrifter, vol. 5, p. 26, 1914.

[30] O. Pettersson, "Long periodical (sic) variations of the tidegenerating force," Publication Circular Conseil Permanent International pour l'Exploration de la Mer, vol. 65, pp. 2-23, 1915.

[31] O. Pettersson, "The tidal force. A study in geophysics," Geografiska Annaler, vol. 18, pp. 261-322, 1930.

[32] I. V. Maksimov and N. P. Smirnov, "A contribution to the study of causes of long-period variations in the activity of the Gulf Stream," Oceanology, vol. 5, pp. 15-24, 1965.

[33] R. G. Currie, "Evidence for 18.6 year MN signal in temperature and drought conditions in North America since AD 1800," Journal of Geophysical Research, vol. 86, no. 11, pp. 1105511064, 1981.

[34] R. G. Currie, "Evidence for 18.6-year lunar nodal drought in western North America during the past millenium," Journal of Geophysical Research, vol. 89, no. 1, pp. 1295-1308, 1984.

[35] R.G. Currie, "Examples and implications of 18.6- and 11year terms in world weather records," in Proceedings of the International Symposium of Climate History, Periodicity, and Predictability, pp. 378-403, Barnard College, Columbia University, 1987, Edited by M. R. Rampino, J. E. Sanders, W. S. Newman and L. K. Konigsson, Van Nostrand Reinhold Publishing, New York, NY, USA, pp. 588.

[36] I. V. Maksimov and N. P. Smirnov, "A long-term circumpolar tide and its significance for the circulation of ocean and atmosphere," Oceanology, vol. 7, pp. 173-178, 1967.

[37] G. Neuman and W. J. Pierson, Principles of Physical Oceanography, Prentice-Hall, Englewood Cliffs, NJ, USA, 1966.

[38] T. C. Royer, "High-latitude oceanic variability associated with the 18.6-year nodal tide," Journal of Geophysical Research, vol. 98, no. 3, pp. 4639-4644, 1993.

[39] H. Yndestad, "Earth nutation influence on the temperature regime of the Barents Sea," ICES Journal of Marine Science, vol. 56, no. 3, pp. 381-387, 1999.

[40] H. Yndestad, A Lunar-Nodal Spectrum in Arctic Time Series, ICES CM, 2003.

[41] H. Yndestad, "The influence of the lunar nodal cycle on Arctic climate," ICES Journal of Marine Science, vol. 63, no. 3, pp. 401-420, 2006.

[42] N. Scafetta, "Empirical evidence for a celestial origin of the climate oscillations and its implications," Journal of Atmospheric and Solar-Terrestrial Physics, vol. 72, no. 13, pp. 951970, 2010.

[43] M. E. Schlesinger and N. Ramankutty, "An oscillation in the global climate system of period 65-70 years," Nature, vol. 367, no. 6465, pp. 723-726, 1994.

[44] C. de Jager, S. Duhau, and B. van Geel, "Quantifying and specifying the solar influence on terrestrial surface temperature," Journal of Atmospheric and Solar-Terrestrial Physics, vol. 72, no. 13, pp. 926-937, 2010. 
[45] R. E. Benestad, I. Hanssen-Bauer, T. E. Skaugen, and E. J. Førland, "Associations between sea-ice and the local climate on Svalbard," Tech. Rep. 07/02, Norwegian Meteorological Institute, 2002.

[46] J.-E. Solheim, H. Humlum, and K. Stordahl, "A relation between the sunspot cycle length and Svalbard temperatures," Advances in Meteorology, vol. 2012, Article ID 543146, 8 pages, 2012. 

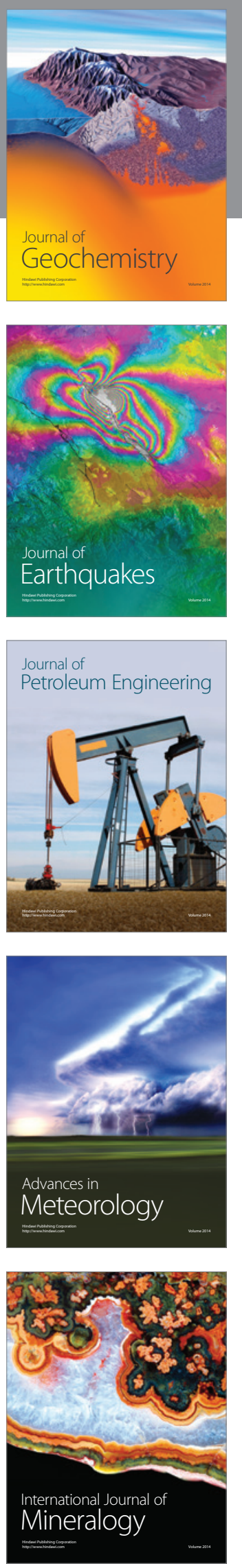
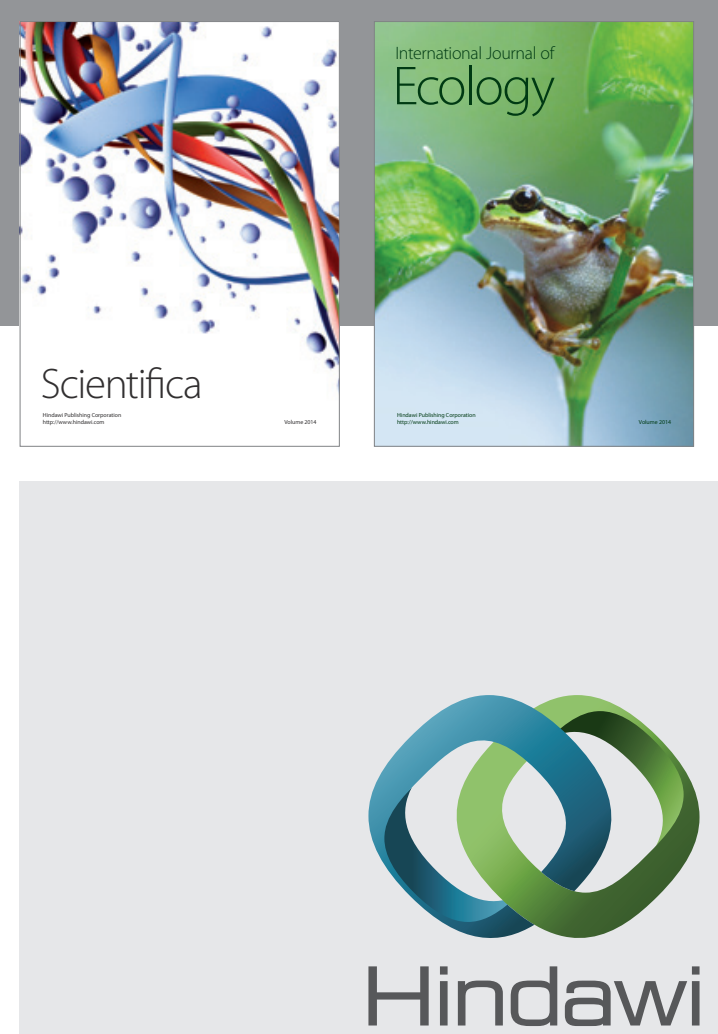

Submit your manuscripts at http://www.hindawi.com
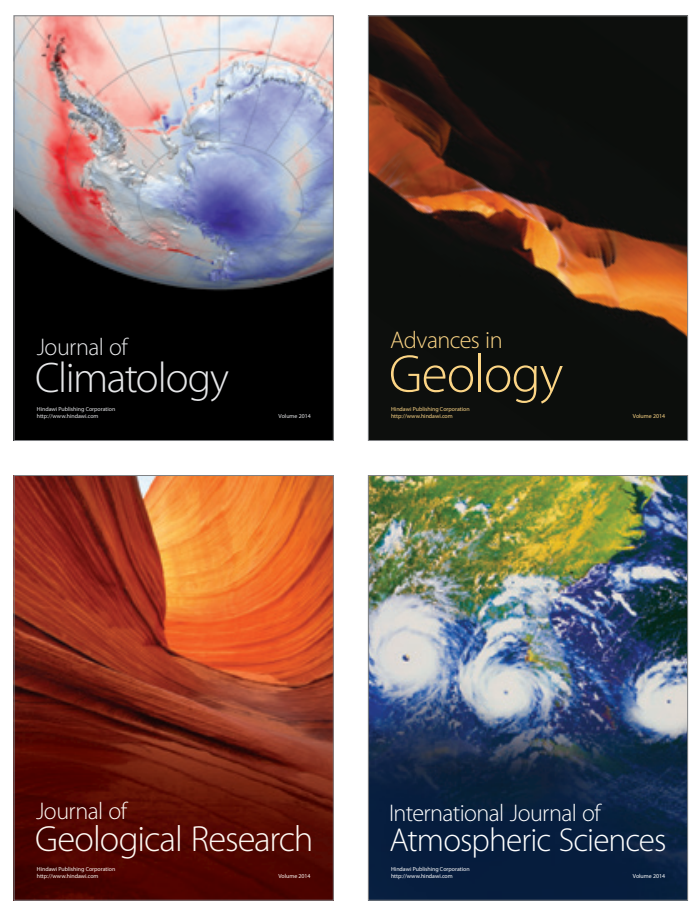
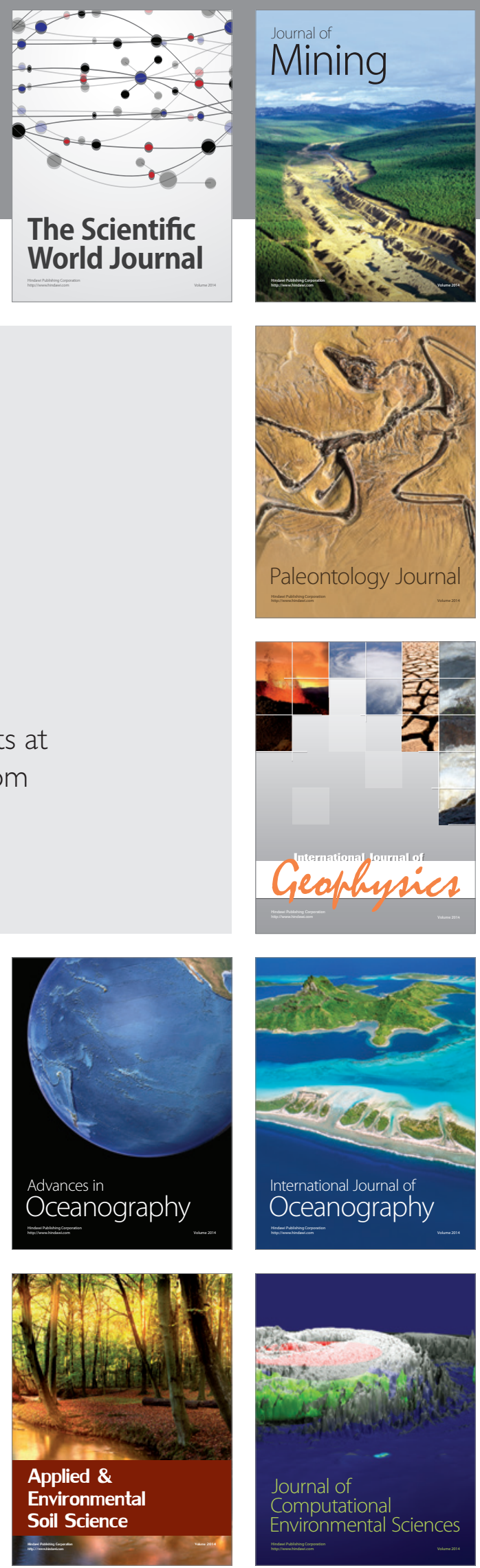